\title{
Revista de Biblioteconomia e Ciência da Informação
}

\section{Onde está a estratégia digital das bibliotecas?: marketing em mídias sociais na Universidade Federal da Paraíba ${ }^{1}$}

\section{Valmira Perucchi}

Doutora em Ciência da Informação pelo

Programa de Pós-Graduação em Ciência da Informação da Universidade de Brasília.

Bibliotecária no Instituto Federal de

Educação, Ciência e Tecnologia da Paraíba.

vperucchi2@yahoo.com.br

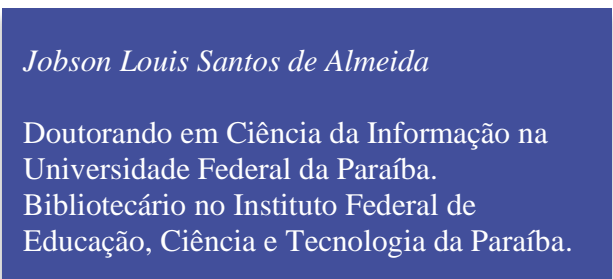

jobsonlouis@gmail.com

\section{Flávia Sena da Silva}

Graduada em Biblioteconomia pela Universidade Federal da Paraíba.

flaviasena.s@gmail.com

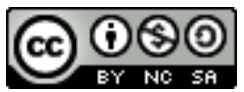

Este trabalho está licenciado com uma Licença Creative Commons - AtribuiçãoNãoComercial-Compartilhalgual 3.0 Brasil.

\begin{abstract}
Resumo
Visa compreender a estratégia digital nas mídias sociais, no contexto do marketing e como esses canais vêm sendo utilizados pelas bibliotecas da Universidade Federal da Paraíba (UFPB). Tem como objetivo geral pesquisar onde está a estratégia digital das bibliotecas por meio do marketing em mídias sociais e como objetivo específico discutir a importância da criação de indicadores qualitativos como estratégia para posicionamento das bibliotecas em mídias sociais, fazendo uma proposta para sua atuação nesse meio. Este trabalho possui natureza quanti-qualitativa e nível exploratório, sendo empregadas as técnicas de pesquisa bibliográfica e documental. O universo de estudo compreende as mídias sociais utilizadas pelo Sistema de Bibliotecas da UFPB conhecido como SISTEMOTECA que é composto por 22 bibliotecas.Foi elaborado a descrição dos indicadores qualitativos propostos tendo por base as quatro fases sugeridas por Strutzel (2015) para um modelo de presença digital, e com base também nos indicadores elaborados por Giroto e Formentini (2018), voltados para websites de arquivos e bibliotecas públicas estaduais, a saber: atração de usuários, interação, conteúdo, promoção, personalização e relacionamento.
\end{abstract}

Palavras-chave: Marketing em mídias sociais. Bibliotecas universitárias. Indicadores qualitativos.

\section{Where is the digital library strategy?: marketing in social media at the federal university of paraiba}

\begin{abstract}
It aims to understand the digital strategy in social media, in the context of marketing and how these channels have been used by the libraries of the Federal University of Paraíba (UFPB). Its general objective is to research where the digital strategy of libraries is through social media marketing and as a specific objective to discuss the importance of creating qualitative indicators as a strategy for positioning libraries on social media, making a proposal for their performance in this medium. This work has a quantitative and qualitative nature and an exploratory level, using bibliographic and documentary research techniques. The study universe comprises the social media used by the UFPB Library System known as SISTEMOTECA which is composed of 22 libraries. The description of the proposed qualitative indicators was elaborated based on the four phases suggested by Strutzel (2015) for a presence model digital, and also based on the indicators elaborated by Giroto and Formentini (2018), aimed at websites of archives and state public libraries, namely: attraction of users, interaction, content, promotion, personalization and relationship.
\end{abstract}

Keywords: Social media marketing. Academic libraries. Qualitative indicators.

\footnotetext{
${ }^{1}$ Este artigo é um desdobramento do Trabalho de Conclusão de Curso "Onde está a estratégia digital das bibliotecas?: Marketing em mídias sociais na UFPB".
} 


\section{Introdução}

As organizações, sejam estas com ou sem fins lucrativos e independente do setor de atuação, têm uma razão de ser e produtos e/ou serviços a oferecer - logo, se inserem em uma relação de troca com o seu público. Nessa conjuntura, o marketing se apresenta como uma disciplina capaz de fomentar e nortear o desenvolvimento de atividades que agreguem valor às ofertas e ao atendimento das necessidades do consumidor, bem como da organização.

Um dos fatores para que uma organização realize o que delineou previamente em seu planejamento, e mesmo para repensar os passos seguintes, é uma comunicação eficaz externa e internamente, além da utilização das informações fornecidas pelo mercado e principalmente pelos seus consumidores, no sentido de elaborar estratégias para fazer-se notar em meio à multidão - mais que isso, conquistar sua atenção e acompanhar suas necessidades.

As bibliotecas certamente estão inseridas nesse contexto e, para acompanharem as mudanças e anseios da sociedade, se torna essencial para estas a consolidação de uma cultura que se atente a compreender as mudanças do entorno e adaptálas à sua realidade. Assim, cabe as bibliotecas tornar proveitoso o que a internet disponibiliza através das mídias sociais e ainda, aproveitar das estratégias de marketing para favorecer a disseminação de informações para promover seu espaço de atuação e ofertar seus produtos e serviços.

A postura constituída pelos aspectos mencionados acima, entre outros, se mostra imprescindível ao refletirmos sobre a velocidade com a qual surgem novas ferramentas, aplicativos, empresas, nichos, hábitos e, sob uma perspectiva mais ampla, novos modos de se comunicar e conectar.

Kotler e Armstrong $(1999$, p. 3) afirmam que marketing é "o processo social e gerencial através do qual indivíduos e grupos obtêm aquilo que desejam e de que necessitam, criando e trocando valores uns com os outros", e com o passar dos anos o foco central desse processo se alterou - e continua se redirecionando - para acompanhar as mudanças sociais que, consequentemente, impactam de forma direta o mercado.

Segundo ressaltado por Silva (2015, p. 21), "com os impactos tecnológicos, e transformações decorrentes, observa-se a necessidade de reestruturação e alteração na forma de relacionamento entre biblioteca e comunidade de usuários". Sob essa perspectiva, a consolidação de uma presença digital pode ser eficaz no sentido de, além dos motivos expostos ao longo do texto até o momento, ser capaz de fornecer métricas que comprovem o envolvimento entre a biblioteca e seu público, fortalecendo sua importância na comunidade em que está inserida.

Observando-se esse panorama e na ânsia de explorar suas possibilidades no âmbito da Biblioteconomia, elegeu-se como objetivo geral pesquisar onde está a estratégia digital das bibliotecas por meio do marketing em mídias sociais e como objetivo específico discutir a importância da criação de indicadores qualitativos como estratégia para posicionamento das bibliotecas em mídias sociais, fazendo uma proposta para sua atuação nesse meio.

Esta pesquisa contribuirá com o campo científico da Biblioteconomia, Arquivologia e Ciência da Informação instigando a reflexão a partir do ponto de vista do Marketing como estratégia digital em mídias digitais nas bibliotecas, sugerindo, indicadores qualitativos, nos quais os bibliotecários gestores possam planejar sua estratégia de marketing para assertiva atuação nas mídias sociais.

\section{Procedimentos Metodológicos}

A presente pesquisa possui natureza quanti-qualitativa e nível exploratório. As técnicas de pesquisa utilizadas são a bibliográfica e documental, dado que foram consultadas fontes primárias e secundárias, como definido por Marconi e Lakatos (2010).

O universo de estudo compreendeu o Sistema de Bibliotecas da Universidade Federal da Paraíba (SISTEMOTECA) que é composto por 22 bibliotecas, a saber, conforme Universidade Federal da Paraíba (2019): Biblioteca Central (BC); Biblioteca Setorial do Centro de Ciências Sociais Aplicadas (BS/CCSA); Biblioteca Setorial do Centro de Comunicação, Turismo e Artes 
(BS/CCTA); Biblioteca Setorial do Centro de Ciências Humanas, Letras e Artes (BS/CCHLA); Biblioteca Setorial do Centro de Ciências Exatas e da Natureza (BS/CCEN); Biblioteca Setorial do Centro de Ciências da Saúde (BS/CCS); Biblioteca Setorial do Centro de Ciências da Saúde (BS/CCS - Escola Técnica de Saúde); Biblioteca Setorial do Centro de Ciências Médicas (BS/CCM); Biblioteca Setorial do Centro de Ciências Jurídicas (BS/CCJ - João Pessoa); Biblioteca Setorial do Centro de Ciências Jurídicas (BS/CCJ - Santa Rita); Biblioteca Setorial do Centro de Educação (BS/CE); Biblioteca Setorial do Centro de Tecnologia (BS/CT); Biblioteca Setorial do Centro de Informática (BS/Cl); Biblioteca Setorial do Centro de Tecnologia e Desenvolvimento Regional (BS/CTDR); Biblioteca Setorial do Núcleo de Documento e Informação Histórica Regional (BS/NDIHR); Biblioteca Setorial do Hospital Universitário (BS/HU); Biblioteca Setorial de Direitos Humanos (BS/DH); Biblioteca Setorial do Centro de Ciências Agrárias - (BS/CCA - Areia); Biblioteca Setorial do Centro de Ciências Humanas, Sociais e Agrárias - Professor José Augusto Trindade (BS/CCHSA); Biblioteca Setorial do Centro de Ciências Humanas, Sociais e Agrárias - Bibliotecária Maria do Socorro Vásquez (BS/CCHSA); Biblioteca Setorial do Centro de Ciências Aplicadas e Educação (BS/CCAE - Rio Tinto); Biblioteca Setorial do Centro de Ciências Aplicadas e Educação (BS/CCAE - Mamanguape).

$\mathrm{Na}$ fase exploratória foi realizada pesquisa bibliográfica na BRAPCI e no Portal de Periódicos da Coordenação de Aperfeiçoamento de Pessoal de Nível Superior (CAPES) a fim de coletar informações de artigos científicos recentes que abordassem a utilização de estratégias de marketing em mídias sociais por bibliotecas universitárias. Pela dificuldade em encontrar trabalhos que se encaixassem nesses critérios, ampliou-se a busca para a utilização de mídias sociais pelas bibliotecas, filtrando-se mais especificamente as bibliotecas universitárias. Foram utilizados os seguintes termos de busca: "Estratégia em mídias sociais", "Marketing digital AND biblioteca", "Mídias sociais AND biblioteca", "Facebook", "YouTube", "Instagram", "Twitter", entre outras variações. A partir das informações coletadas e apresentadas na fundamentação teórica, foi possível obter um panorama atual do fenômeno, que é o objetivo da pesquisa exploratória (GONSALVES, 2001).

Em seguida foi feita a pesquisa documental, na qual utilizou-se a Resolução no 31 de 2009 da UFPB, que dispõe do regimento interno do SISTEMOTECA, para delimitação do campo de pesquisa, onde foi possível obter informações sobre seu objetivo e definir as bibliotecas que fazem parte do sistema, com dados complementados pela página da web da Biblioteca Central.

Continuando a pesquisa documental, foi elaborado a descrição dos indicadores qualitativos propostos tendo por base as quatro fases sugeridas por Strutzel (2015) para um modelo de presença digital, apresentadas no tópico 3, e os indicadores elaborados por Giroto e Formentini (2018), voltados para websites de arquivos e bibliotecas públicas estaduais, a saber: atração de usuários, interação, conteúdo, promoção, personalização e relacionamento.

\section{Mídias sociais e presença digital}

Em 2004 se falava pela primeira vez em Web 2.0, termo utilizado em uma conferência de brainstorming entre O'Reilly e a MediaLive International (O’REILLY, 2005), configurando um cenário em que seria possível não só receber informações de modo passivo, como em sua predecessora Web 1.0, mas também promover a interação com o conteúdo, através de comentários, compartilhamentos e outras ferramentas. Conhecida como Web Social,

a Web 2.0 pode ser considera (sic) uma nova concepção, pois passa agora a ser descentralizada e na qual o sujeito torna-se um ser ativo e participante sobre a criação, seleção e troca de conteúdo postado em um determinado site por meio de plataformas abertas (BLATTMAN; SILVA, 2007, p. 198).

Foi nesse contexto que as mídias sociais deram seus primeiros passos, as quais pode-se definir como "ferramentas baseadas em interação social, e que tem como base pessoas que se juntam e interagem por alguma razão onde é possível a produção de conteúdo descentralizado" (CALIL JUNIOR; CORRÊA; SPUDEIT, 2013, p. 5). Entretanto, as mudanças foram além de um novo ambiente de interação. Recuero (2011, p. 14) afirma que o que se entende por mídia social atualmente

compreende um fenômeno complexo, que abarca o conjunto de novas tecnologias de comunicação mais participativas, mais rápidas e mais populares e as apropriações que foram e que são geradas em torno dessas ferramentas. É um momento de hiperconexão em rede, onde estamos não apenas conectados, mas onde transcrevemos nossos grupos sociais e, através do suporte, geramos novas formas de circulação, filtragem e difusão dessas informações.

As mídias sociais estão entre os principais aplicativos utilizados, colocando o Brasil em segundo lugar no ranking de maior tempo de uso diário dessas plataformas, segundo pesquisa feita pela Globalwebindex (2019). Facebook, YouTube, WhatsApp, 
Facebook Messenger, WeChat e Instagram figuram no topo do ranking global de popularidade, conforme dados divulgados pela Statista (2019a), apresentados no Gráfico 1.

Gráfico 1 - Mídias sociais mais populares do mundo em 2019

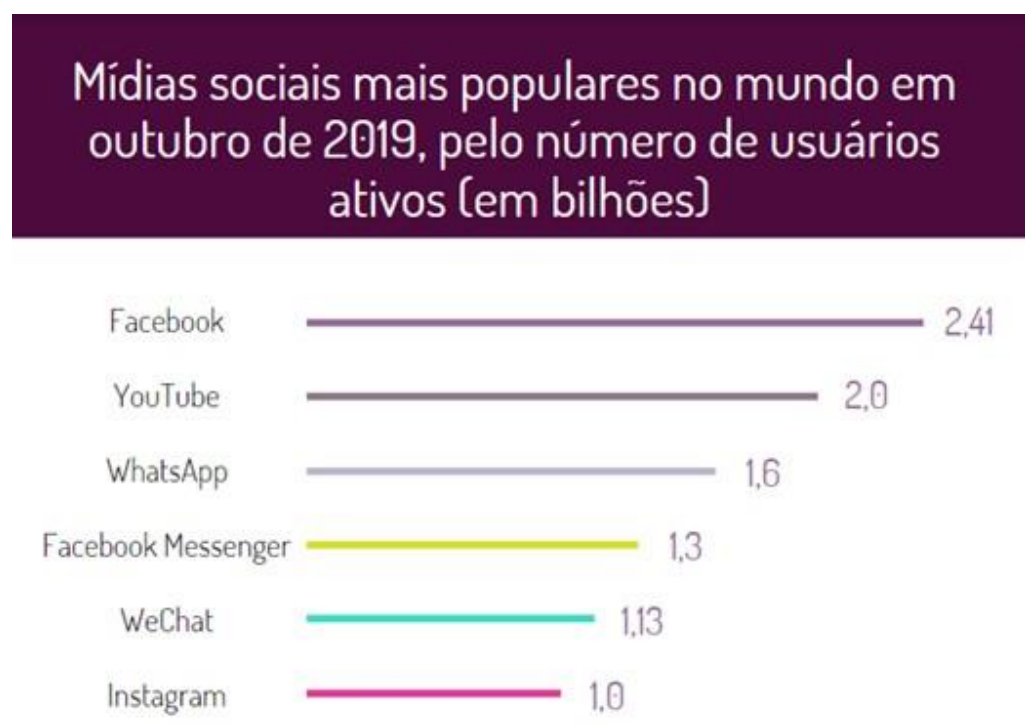

Fonte: Adaptado a partir de dados da Statista (2019a).

Mais especificamente no Brasil, o WeChat sai da lista e o Twitter é incorporado, pelo relatório da We are social e Hootsuite (2019) elaborado através de pesquisa aplicada entre usuários da internet na faixa de 16 a 44 anos, como mostra o Gráfico 2.

Gráfico 2 - Mídias sociais mais ativas no Brasil em 2019

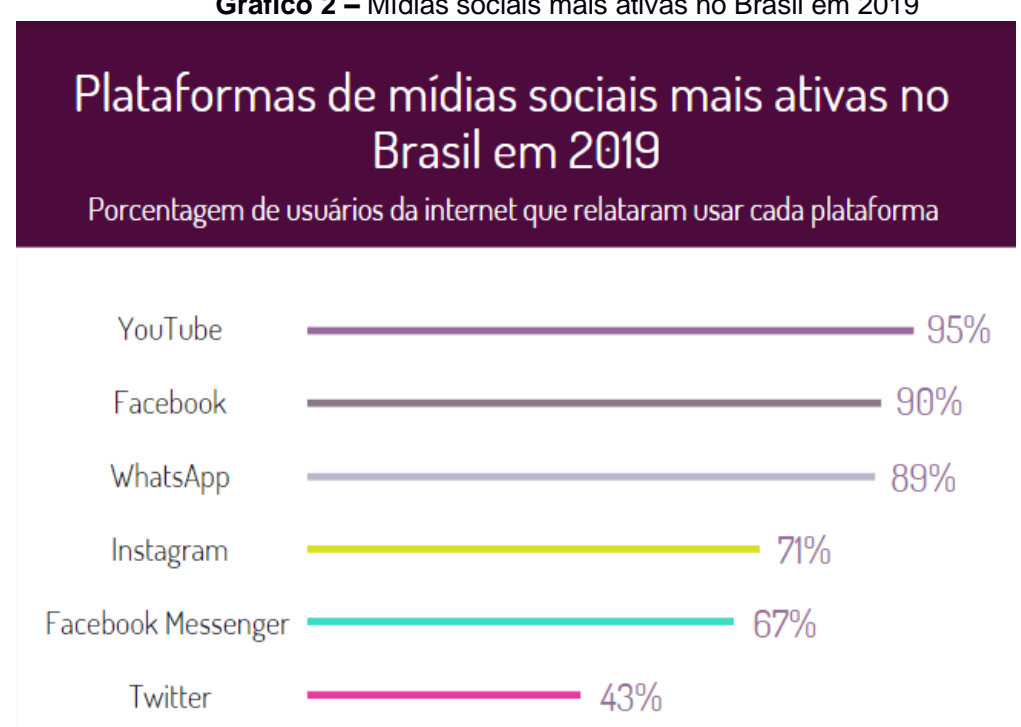

Fonte: Adaptado a partir do relatório da We are social e Hootsuite (2019).

Colocando em perspectiva a consolidação do uso de dispositivos conectados à internet e a popularização das mídias sociais, como exemplificado acima, estas não poderiam deixar de se tornar mais um meio no qual organizações dos mais diversos setores se comuniquem e estabeleçam sua imagem perante seus clientes e usuários. Em projeção feita pela Statista (2019b) exposta no Gráfico 3, a expectativa é de que a quantidade de usuários das mídias sociais continue a aumentar, caracterizando esses canais como pontos de contato cada vez mais promissores, pois através da integração de suas ferramentas de 
comunicação e compartilhamento, permitem que os usuários interajam entre si e com as organizações de forma prática e acessível.

Gráfico 3 - Número de usuário de mídias sociais no Brasil 2017-2023

\section{Número de usuários de mídias sociais no}

Brasil de 2017 até 2023 (em milhões)

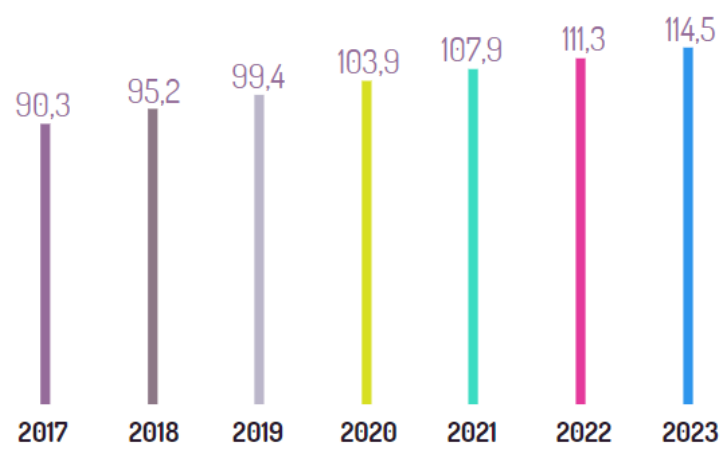

Fonte: Adaptado a partir de dados da Statista (2019b).

As mídias sociais podem ser divididas em 6 categorias, conforme Kaplan e Haenlein (2010), apresentadas no Quadro 1. Estas oferecem ferramentas diversificadas que, dentre outras opções, disponibilizam insights sobre o perfil, interações e comportamento dos usuários e o impulsionamento do conteúdo para o público selecionado, de acordo com os interesses da organização, sendo esses apenas alguns exemplos entre uma gama de alternativas.

Quadro 1 - Categorização de mídias sociais

\begin{tabular}{|c|c|}
\hline Tipos & Descrição \\
\hline Projetos colaborativos & $\begin{array}{l}\text { Permitem a criação de conteúdo de forma conjunta e simultânea por vários usuários finais, } \\
\text { que adicionam, alteram e removem informações, e a criação de coleções e avaliação, em } \\
\text { grupo, de links da internet e conteúdo de mídia. Exemplos: Wikipedia e Delicious. }\end{array}$ \\
\hline Blogs & $\begin{array}{l}\text { Um dos primeiros formatos conhecidos, são páginas normalmente gerenciadas por uma só } \\
\text { pessoa, que podem possuir conteúdo pessoal ou sobre assuntos selecionados, apresentado } \\
\text { em forma de publicação marcadas por data e hora, organizadas da mais recente para a mais } \\
\text { antiga. }\end{array}$ \\
\hline Comunidades de conteúdo & $\begin{array}{l}\text { Tem como principal objetivo o compartilhamento de conteúdo de mídia entre os usuários, } \\
\text { existindo para uma grande variedade de tipos. Exemplos: Flickr (fotos), YouTube (vídeos), } \\
\text { SlideShare (apresentações de PowerPoint), entre outros. }\end{array}$ \\
\hline Sites de redes sociais & $\begin{array}{l}\text { Possibilitam a criação de perfis pelos usuários, nos quais se conectam com amigos, } \\
\text { compartilham conteúdo e enviam mensagens instantâneas. Exemplos: Facebook, } \\
\text { Instagram, Twitter, entre outros. }\end{array}$ \\
\hline Mundos de jogos virtuais & $\begin{array}{l}\text { Replicam um ambiente tridimensional no qual seus usuários criam avatares e interagem } \\
\text { entre si de acordo com as regras impostas pelo jogo. Exemplo: World of Warcraft. }\end{array}$ \\
\hline Mundos sociais virtuais & $\begin{array}{l}\text { Possuem avatares e admitem interação entre os jogadores assim como na categoria } \\
\text { anterior, porém há praticamente uma emulação do mundo real e os usuários têm maior } \\
\text { liberdade com relação ao comportamento no mundo virtual. Exemplo: Second Life. }\end{array}$ \\
\hline
\end{tabular}

Fonte: Adaptada a partir de Kaplan e Haenlein (2010, tradução nossa).

Segundo Strutzel (2015, p. 41), "com o público mais ativo nas mídias digitais e sociais, o engajamento se dá muito mais por parte do consumidor. Entretanto as marcas, por sua vez, precisam viabilizar os canais e ferramentas para o engajamento acontecer espontaneamente" através do estabelecimento de uma presença digital, conforme defendido pelo autor, que propõe quatro fases para alcançar um modelo adequado, sendo estas: 
- Existência: se refere a fazer-se presente e principalmente adotar um pensamento voltado para a cultura digital, no sentido de implementar ações em todos os setores, com o intuito de facilitar os processos comumente desenvolvidos na organização;

- Atração: abrange o planejamento e estruturação dos aspectos relacionados à produção de materiais voltados ao público alvo identificado, cronogramas, definição de frequência de exposição, e que canais serão adotados para as ações programadas;

- Relacionamento: está relacionada com o monitoramento do feedback do público, até mesmo nas mídias em que a organização não está presente, a fim de avaliar os resultados das ações implementadas, possibilitando a compreensão de oscilações de interação, sanar questionamentos que porventura surjam, além de ajustes e melhorias no conteúdo;

- Engajamento: se trata do nível de interação dos usuários com o conteúdo publicado, também exigindo monitoramento e avaliação através de métricas, que podem variar de um canal para o outro.

Diante do exposto, cabe às organizações estabelecer ações e refletir acerca destas, visando o planejamento e/ou reavaliação de suas estratégias em relação à comunicação com seu público, na premência de mantê-la e ampliá-la, considerando o fluxo de mudanças e transformações constantes (CORRÊA, 2009, p. 163).

\section{Indicadores qualitativos em ambiente digital como estratégia para o Marketing digital nas bibliotecas da UFPB}

O SISTEMOTECA, é um conjunto de Bibliotecas integradas sob os aspectos funcional e operacional, tendo por objetivo a unidade e harmonia das atividades educacionais, científicas tecnológicas e culturais da UFPB, voltadas para a coleta, tratamento, armazenagem, recuperação e disseminação de informações, para o apoio aos programas de ensino, pesquisa $e$ extensão (UNIVERSIDADE FEDERAL DA PARAÍBA, 2009, p. 2).

No Regimento do SISTEMOTECA, em seu artigo 22, prevê para a Gestão de Marketing Bibliotecário/Informação, entre outras competências, "identificar a imagem da Biblioteca e mantê-la positiva por meio de ferramentas de comunicação qualitativa/interativa com o usuário" (UNIVERSIDADE FEDERAL DA PARAÍBA, 2009, p. 9). De acordo com a pesquisa documental e bibliográfica realizada, e as ideias e exemplos expostos neste trabalho, as mídias sociais se enquadram como ferramentas de comunicação e têm público e características particulares que devem ser avaliadas em comparação aos usuários da biblioteca. Pontes e Santos (2011, p. 4) afirmam, ampliando o contexto da comunicação, que

A utilização das Redes Sociais Virtuais dentro das Bibliotecas Universitárias visa apoiar as políticas organizacionais, o gerenciamento das informações e o processo de comunicação, auxiliando na obtenção de novos conhecimentos, favorecendo a interação de fontes internas e externas de informação e uma maior aproximação com todos os segmentos de ensino, pesquisa e extensão que atende.

Essa perspectiva agrega valor ao uso das mídias sociais pelas bibliotecas, uma vez que, quando bem gerenciadas, possibilitam a materialização dos objetivos da instituição.

Os indicadores qualitativos propostos visam associar os aspectos comumente observados nas mídias sociais, em seu espectro geral, aos objetivos da biblioteca como organização, considerando algumas de suas peculiaridades, pautando-se nos princípios do marketing.

Tomando o marketing como uma filosofia de gestão que gera estratégias diversificadas para os canais escolhidos mediante planejamento, entende-se que este, ao ser aplicado em ambiente digital, é comumente designado pelo termo marketing digital e definido como aquele que "utiliza estratégias com algum componente digital no marketing mix - produto, preço, praça ou promoção" (GABRIEL, 2010, p. 104).

O estabelecimento de indicadores qualitativos se constitui como estratégia para a atuação das bibliotecas em ambiente digital, posto que possibilitam o acompanhamento dos resultados ao longo do tempo e compõem ferramentas vantajosas para planejamento e avaliação de ações nesse contexto. Portanto, propõe-se os seguintes indicadores qualitativos para a atuação 
das bibliotecas em mídias sociais, expostos no Quadro 2, tomando por base as quatro fases sugeridas por Strutzel (2015) para um modelo de presença digital, apresentadas no tópico 3, e os indicadores elaborados por Giroto e Formentini (2018), voltados para websites de arquivos e bibliotecas públicas estaduais, a saber: atração de usuários, interação, conteúdo, promoção, personalização e relacionamento.

Quadro 2 - Descrição dos indicadores qualitativos propostos

\begin{tabular}{|c|c|}
\hline Atração de usuários & $\begin{array}{l}\text { Levantamento de horários de maior acesso, faixa etária, entre outras métricas } \\
\text { disponibilizadas na mídia social, assim como os dados constantes no sistema de } \\
\text { gestão da instituição de ensino com relação aos usuários; e estabelecimento de metas } \\
\text { a atingir, buscando integrar as necessidades e perfil do público aos produtos e serviços } \\
\text { oferecidos pela biblioteca. }\end{array}$ \\
\hline $\begin{array}{l}\text { Disponibilização de } \\
\text { informações }\end{array}$ & $\begin{array}{l}\text { Usar de modo eficaz os locais de destaque no perfil, expondo as informações de } \\
\text { contato, localização, horários e perguntas frequentes. }\end{array}$ \\
\hline Relacionamento & $\begin{array}{l}\text { Acompanhamento dos comentários, com o intuito de valorizar a opinião dos usuários, } \\
\text { responder questionamentos e articular ações para amenizar descontentamentos e } \\
\text { possíveis conflitos; e disponibilização de canais para comunicação, sejam eles dentro } \\
\text { ou fora da mídia social, estipulando respostas padrão para serem utilizadas como base } \\
\text { em caso de perguntas frequentes. }\end{array}$ \\
\hline Personalização & $\begin{array}{l}\text { Cadastro do logo da instituição nos locais viabilizados pela mídia social, a exemplo de } \\
\text { imagens de perfil e capa; e produção de imagens e identidade visual própria, } \\
\text { transmitindo seriedade, facilitando o reconhecimento do conteúdo publicado, bem } \\
\text { como evitando quebra de direitos autorais ao utilizar material obtido de modo } \\
\text { corriqueiro pela internet. }\end{array}$ \\
\hline Promoção & $\begin{array}{l}\text { Definição de cronograma de publicações e estruturação de materiais a serem } \\
\text { produzidos, considerando as especificidades de cada público e mídias selecionadas; } \\
\text { utilização dos recursos oferecidos pela mídia, a fim de criar vínculo com o público } \\
\text { através da interatividade e participação; e incentivo ao uso de outros serviços digitais } \\
\text { oferecidos pela biblioteca (por exemplo: bases de dados, biblioteca virtual, repositório } \\
\text { institucional), seja através de links, tutoriais, entre outros, estruturando essa ação de } \\
\text { modo que a transição de uma plataforma para outra seja prática e intuitiva. }\end{array}$ \\
\hline Acessibilidade & $\begin{array}{l}\text { Identificação e estruturação de mecanismos facilitadores para pessoas com } \\
\text { deficiência, como a descrição de imagens, principalmente aquelas que possuem } \\
\text { informações relevantes, geralmente acompanhada de \#paracegover. }\end{array}$ \\
\hline Formalização & $\begin{array}{l}\text { Existência de guia, manual ou diretriz, entre outros documentos possíveis, que } \\
\text { formalize os processos realizados para a concretização das ações determinadas, } \\
\text { facilitando o acesso e transmissão das informações quanto à sua execução. }\end{array}$ \\
\hline
\end{tabular}

Fonte: Elaborado pelos autores, 2020.

$\mathrm{Na}$ "Atração de usuários", são englobados os aspectos concernentes ao estudo e planejamento das ações a serem desenvolvidas, avaliando-se a estruturação de metas a partir do que foi levantado sobre os usuários e o que a biblioteca pretende alcançar; a "Disponibilização de informações" diz respeito à sistematização das informações relevantes nos pontos de destaque oferecidos pela mídia social a fim de que sejam facilmente consultadas; o "Relacionamento" abrange a comunicação direta com os usuários, a análise das reações para atuar a partir do que foi observado, e a adoção de mecanismos que facilitem e tornem o diálogo mais eficiente; a "Personalização" agrega elementos no que se refere à caracterização do perfil de acordo com a biblioteca; a "Promoção" incorpora o planejamento do conteúdo, sua elaboração e frequência de publicação, utilizando os recursos da mídia social e a utilização desse canal como direcionador aos diversos produtos e serviços da biblioteca; a "Acessibilidade" integra mecanismos para a inclusão de pessoas com deficiência, para garantir que esse público seja atendido; e por fim, a "Formalização", que identifica a existência de documento que formalize as atividades realizadas. 
É importante compreender que são vários os elementos envolvidos na experiência proporcionada pelas mídias sociais, sendo vital analisá-las individualmente no que concerne às suas características e recursos oferecidos, à forma que o público as utiliza, bem como o tipo de conteúdo que esperam encontrar, efetuando as devidas adaptações no seu uso, monitoramento e avaliação, também buscando adotar ferramentas que auxiliem sua gestão, tais como o Google Analytics, entre outros serviços que fornecem dados para aprimorar e acompanhar os resultados obtidos.

\section{Considerações Finais}

Por meio do levantamento de artigos científicos referentes à inserção das bibliotecas nas mídias sociais, foi observado como ponto comum indícios do seu uso não planejado, resultando em baixo engajamento do público. São apontadas como possíveis justificativas: preferência por outra estratégia de comunicação, baixa disponibilidade de tempo entre a equipe, desinteresse dos usuários, entre outras.

Para tanto, incitou-se a discussão de criação de indicadores qualitativos para atuação de bibliotecas em mídias sociais e fezse uma proposta, com a intenção de nortear os bibliotecários gestores quanto à utilização dessas ferramentas e a mensuração de seus resultados. Trata-se de um ponto de partida, uma vez que é uma temática pouco explorada e a presença digital das bibliotecas é tímida, sendo necessária a realização de estudos sob outras perspectivas, tais como as variáveis que influenciam o contexto atual e a aplicabilidade e estudo de caso de estratégias mais específicas.

Enfatiza-se que a observação e adaptação são primordiais para a inserção e atuação efetivas das bibliotecas em contexto digital, o qual se apresenta cada vez mais intrínseco nas mais diversas conjunturas, demandando ação dos bibliotecários gestores e planejamento para implementação de uma cultura organizacional compatível, com vistas de fortalecer a biblioteca e sua missão de acesso e disseminação da informação independente da esfera em que seja requisitada.

\section{Referências}

BLATTMAN, Ursula; SILVA, Fabiano Couto Corrêa da. Colaboração e interação na web 2.0 e biblioteca 2.0. Revista ACB:

Biblioteconomia em Santa Catarina, Florianópolis, v. 12, n. 2, p. 191-215, jul./dez.2007. Disponível em:

https://revista.acbsc.org.br/racb/article/view/530/664 Acesso em: 26 out. 2019.

CALIL JUNIOR, Alberto; CORRÊA, Elisa Cristina Delfini; SPUDEIT, Daniela. O uso das mídias sociais nas bibliotecas brasileiras: análise dos trabalhos apresentados no SNBU e CBBD. In: CONGRESSO BRASILEIRO DE BIBLIOTECONOMIA, DOCUMENTAÇÃO E CIÊNCIA DA INFORMAÇÃO, 25., 2013, Florianópolis. Anais eletrônicos... [S.I.]: FEBAB, 2013. Disponível em: http://portal.febab.org.br/anais/article/view/1634/1635 Acesso em: 21 nov. 2019.

CORRÊA, Elizabeth Saad. A comunicação digital nas organizações: tendências e transformações. Organicom, São Paulo, v. 6, n. 10-11, p. 161-167, 2009. Disponível em: http://www.revistas.usp.br/organicom/article/view/139020 Acesso em: 25 out. 2019.

GABRIEL, Martha. Marketing na era digital: conceitos, plataformas e estratégias. São Paulo: Novatec, 2010.

GIROTO, Luan; FORMENTINI, Rosangela. Estratégia de marketing digital para unidades informacionais: estudo dos websites de arquivos e bibliotecas públicas estaduais. InCID: Revista de Ciência da Informação e Documentação, v. 8, n. 2, p. 144-162, set. 2017/fev. 2018. Disponível em: http://www.revistas.usp.br/incid/article/view/128998/133888 Acesso em: 29 jan. 2020.

GLOBALWEBINDEX. Social: GlobalWeblndex's flagship report on the latest trends in social media. [S.I.: s.n.], 2019. Disponível em: https://www.globalwebindex.com/hubfs/Downloads/2019\%20Q1\%20Social\%20Flagship\%20Report.pdf?utm campaign=Social\%20report\%2 0July\%202019\&utm source=hs automation\&utm medium=email\&utm content=74226065\& hsenc=p2ANgtz- f5z46jzy42EpSr81We9p37eJKZj68 Ts0lAedelq7hTDoTu9JWZb5BBYuCWdPI2wOoJpjFN4N1pduOngAZQCIICBJg\& hsmi=74226065. Acesso em: 25 out. 2019.

GONSALVES, Elisa Pereira. Conversas sobre iniciação à pesquisa científica. Campinas: Alínea, 2001.

KAPLAN, Andress; HAENLEIN, Michael. Users of the world, unite! The challenges and opportunities of Social Media. Business Horizons, [S.I.], v. 53, n. 1, p. 59-68, 2010.

KOTLER, Phillip; ARMSTRONG, Gary. Princípios de marketing. 7. ed. Rio de Janeiro: LTC, 1999.

MARCONI, Marina de Andrade; LAKATOS, Eva Maria. Fundamentos de metodologia científica. 7. ed. São Paulo: Atlas, 2010.

O'REILLY, Tim. What is web 2.0: design patterns and business models for the next generation software, 2005. Disponível em: https://www.oreilly.com/pub/a/web2/archive/what-is-web-20.html Acesso em: 1 dez. 2019. 
PONTES, Euzébia Maria; SANTOS, Mônica Karina. O uso das redes sociais no âmbito das bibliotecas universitárias brasileiras. In: CONGRESSO BRASILEIRO DE BIBLIOTECONOMIA, DOCUMENTAÇÃO E CIÊNCIA DA INFORMAÇÃO, 24., 2011, Maceió. Anais eletrônicos... [S.I.: s.n.], 2011. Disponível em: https://repositorio.ufrn.br/ispui/bitstream/1/6205/1/370-2620-1-PB.pdf Acesso em: 24 jan. 2020.

RECUERO, Raquel. A nova revolução: as redes são as mensagens. In: BAMBRILLA, A. (Org.). Para entender as mídias sociais. [S.I.: s.n.], 2011. Disponível em: https://issuu.com/anabrambilla/docs/paraentenderasmidiassociais Acesso em: 20 nov. 2019.

SILVA, José Fernando Modesto. Biblioteca pública, internet e os impactos tecnológicos. In: SILVA, J. F. M. (Org.). A biblioteca pública em contexto: cultural, econômico, social e tecnológico. Brasília: Thesaurus, 2015.

STATISTA. Most popular social networks worldwide as of October 2019, ranked by number of active users (in millions), $2019 \mathrm{a}$. Disponível em: https://www.statista.com/statistics/272014/global-social-networks-ranked-by-number-of-users/ Acesso em: 21 nov. 2019.

STATISTA. Number of social network users in Brazil from 2017 to 2023 (in millions), 2019b. Disponível em: https://www.statista.com/statistics/272014/global-social-networks-ranked-by-number-of-users/ Acesso em: 4 dez. 2019.

STRUTZEL, Tércio. Presença digital: estratégias eficazes para posicionar sua marca pessoal ou corporativa na web. Rio de Janeiro: Alta Books, 2015.

UNIVERSIDADE FEDERAL DA PARAÍBA. Resolução no 31, de 2009. Aprova o Regimento interno do Sistema de Bibliotecas da UFPB. João Pessoa: Conselho Universitário da Universidade Federal da Paraíba, 2009. Disponível em:

http://www.biblioteca.ufpb.br/biblioteca/contents/documentos/regimento-biblioteca-central-2009.pdf/view Acesso em: 1 jan. 2020.

UNIVERSIDADE FEDERAL DA PARAÍBA. Sistema de Bibliotecas. Sistema de Bibliotecas da UFPB. João Pessoa: 2019. Disponível em: http://www.biblioteca.ufpb.br/biblioteca/contents/menu/biblioteca-1/copy of sistemoteca Acesso em 10 jan. 2019.

WE ARE SOCIAL; HOOTSUITE. Digital 2019: Brazil. [S.I.: s.n.], 2019. Disponível em: https://datareportal.com/reports/digital-2019-brazil Acesso em: 22 nov. 2019.

\section{UNIVERSIDADE
FEDERAL DO CARIRI}

Centro de Ciências Sociais Aplicadas

Mestrado Profissional em Biblioteconomia

Este periódico é uma publicação do Programa de Pós-Graduação em Biblioteconomia da Universidade Federal do Cariri em formato digital e periodicidade quadrimestral. 